Article

\title{
Fatigue Characteristics of Fe-Based Shape-Memory Alloys
}

\author{
Ki-Nam Hong, Yeong-Mo Yeon*(D), Won-Bo Shim and Sang-Won Ji \\ Department of Civil Engineering, Chungbuk National University, 1 Chungdae-ro, Seowon-Gu, Cheongju, \\ Chungbuk 28644, Korea; hong@chungbuk.ac.kr (K.-N.H.); firstice@chungbuk.ac.kr (W.-B.S.); \\ tkddnjs0727@chungbuk.ac.kr (S.-W.J.) \\ * Correspondence: yym235@chungbuk.ac.kr; Tel.: +82-10-6400-3092
}

Received: 28 July 2020; Accepted: 20 August 2020; Published: 22 August 2020

check for updates

\begin{abstract}
This study reports the details of an experimental study of fatigue behavior of two types of Fe-based shape-memory alloys (Fe-SMAs). The two types of Fe-SMAs developed for this study were used to prepare specimens according to ISO 12106 standards. All fatigue tests were conducted under a constant frequency of five hertz using a universal testing machine with a capacity of $100 \mathrm{kN}$. The stress ratio applied to the test was zero, and the fatigue tests were conducted until the number of loading cycles exceeded two million, by reducing the stress range from $700 \mathrm{MPa}$ by $100 \mathrm{MPa}$ for each test. At stress range of $700 \mathrm{MPa}$, the number of loading cycles that has a large ultimate elongation, was greater for the B-type alloy than the A-type alloy. On the other hand, the number of loading cycles at the low stress range below the yield strength was found to be higher in the A-type alloy, which had a higher yield strength than in the B-type alloy. Additionally, by analyzing the S-N relationship and performing a first order regression analysis for the test results, it was confirmed that the fatigue limits of the A-type and B-type alloys are $473 \mathrm{MPa}$ and $330 \mathrm{MPa}$, respectively.
\end{abstract}

Keywords: Fe-based shape-memory alloy (Fe-SMA); recovery stress; recovery strain; fatigue properties

\section{Introduction}

Shape-memory alloys (SMAs) are special alloys that can restore their original shape through heating and cooling - even if plastic deformation exceeding their elastic deformation capacity occurs [1]. This recovery performance is called a shape memory effect (SME), and more than 30 alloys including $\mathrm{Ni}-\mathrm{Ti}$ alloy (nitinol) having this property have been reported [2]. In particular, nitinol has excellent recovery performance and is used in various fields such as the aerospace industry, machinery and medical devices [3]. However, the high raw material price of nitinol is regarded as an obstacle to the application of this alloy to the civil and architectural fields [4,5].

Since Sato et al. [6] developed Fe-based shape-alloy alloys (Fe-SMAs) in 1982, research has been actively conducted to apply these alloys to the construction and civil engineering fields. Shahverdi et al. [7] conducted a study to use stripes made of Fe-SMA as reinforcements for the near-surface mounted method (NSM). They reported that specimens with activated stripes have an increased crack load of about 80\% compared to those with inactivated stripes. Rojob et al. [8] conducted a study to utilize bars made of Fe-SMA as reinforcements for the NSM method. Through the results of the experiment, they confirmed that strengthening of RC structures using the Fe-SMA bars can secure high ductility, in contrast with strengthening of structures by FRP. Michelle et al. [9] strengthened reinforced concrete beams with Fe-SMA plates by an externally bonded method. They confirmed that specimens reinforced with Fe-SMA plates showed higher cracking loads than specimens reinforced with carbon fiber reinforced polymer (CFRP) due to prestressing force. Schranz et al. [10] evaluated the 
mechanical properties and recovery characteristics of ribbed Fe-SMA bars with a diameter of $12 \mathrm{~mm}$ and $16 \mathrm{~mm}$ and proposed a stress-strain model of Fe-SMA bar.

Civil structures have higher risk of fatigue failure due to cyclic loading than the risk of destruction due to static overload [11]. In particular, unlike normal flexural failure, fatigue failure occurs at a much lower stress than static fracture stress, and most cases exhibit sudden brittle fracture behavior [11]. In addition, if a Fe-SMA is used as the prestressing tendon of bridges or railway structures, it can be expected to receive millions of cyclic loads, and thus a review of its fatigue performance is essential.

However, most of the existing research on Fe-SMA has been aimed at identifying the mechanical and recovery characteristics of the material, and there is a lack of research focused on evaluating fatigue characteristics. Therefore, fatigue tests for two types of alloys developed through previous studies conducted by these authors are reported in this study. One is an alloy applicable to elements requiring high recovery stress such as prestress tendons and the other is an alloy applicable to elements requiring high recovery strain such as pipe couplers. In addition, the fatigue test results were used to analyze the S-N correlation of the Fe-SMAs and to present their fatigue limits. The fatigue performance of the alloy manufactured by the process generally applied to the manufacture of Fe-SMA was evaluated in this study. Therefore, this study is expected to be referred to as meaningful data in evaluating the fatigue performance of this kind of alloy.

\section{Materials}

\subsection{Production of Fe-SMAs}

In this study, fatigue tests were conducted using two types of Fe-SMA plates with chemical composition as listed in Table 1. In order to fabricate each Fe-SMA plate, $50 \mathrm{~kg}$ of ingot was produced using a vacuum-induction melting device. The ingot fabricated for alloy homogenization was heat treated at $1250{ }^{\circ} \mathrm{C}$ for $6 \mathrm{~h}$. It was manufactured to be 5 -mm-thick by performing hot rolling at $1000{ }^{\circ} \mathrm{C}$ after completing the heat treatment. The B-type alloy was heat treated at $750{ }^{\circ} \mathrm{C}$ for two hours to dissipate the internal stress generated by hardening.

Table 1. Chemical composition of Fe-SMA [12].

\begin{tabular}{ccc}
\hline Type of SMA & Chemical Composition (weight $\%$ ) & Heat Treatment \\
\hline A-type & Fe-17Mn-5Si-5Cr-0.3C-1Ti & Non-heat treatment \\
B-type & Fe-17Mn-5Si-5Cr-4Ni-0.1C & Heat treatment \\
\hline
\end{tabular}

\subsection{Mechanical Properties of Fe-SMAs}

A direct tensile test was performed to determine the mechanical properties of the Fe-SMAs used in this study. Specimens were prepared according to ASTM A370 [13] standards and tested with a $100 \mathrm{kN}$ universal testing machine. Figure 1 and Table 2 show the stress-strain curves and mechanical properties of each Fe-SMA, respectively. The elastic modulus of the A-type and B-type Fe-SMAs was similar, i.e., $124.57 \mathrm{GPa}$ and 123.26 GPa, respectively. As shown in Figure 1, the Fe-SMAs do not exhibit an exact yielding point, unlike ordinary rebars. Deriving the yield point of the Fe-SMAs using the $0.2 \%$ offset method, the yield strengths of A-type and B-type alloys were determined as $599 \mathrm{MPa}$ and $410 \mathrm{MPa}$, respectively. The ultimate strength of the A-type alloy was $1140 \mathrm{MPa}$, whereas the ultimate strength of the B-type alloy was found to be $1080 \mathrm{MPa}-5 \%$ smaller than that of the A-type alloy. On the other hand, the ultimate strains of the A-type and B-type alloys were 0.22556 and 0.39510 , respectively, indicating that the B-type alloy has more ductile behavior than the A-type alloy. The ultimate strain and ultimate strength of the $\mathrm{Fe}-17 \mathrm{Mn}-10 \mathrm{Cr}-4 \mathrm{Ni}-1(\mathrm{~V}, \mathrm{C})$ alloy having a chemical composition similar to that of the B-type alloy were reported as 0.28 and $868 \mathrm{MPa}$, respectively [9]. These values are relatively small compared to those of the B-type alloy. In addition, $\mathrm{Fe}-17 \mathrm{Mn}-10 \mathrm{Cr}-4 \mathrm{Ni}-1(\mathrm{~V}, \mathrm{C})$ and B-type did not contain titanium carbide ( $\mathrm{TiC})$, so the ultimate strength was lower than that of the A-type alloy [14]. 


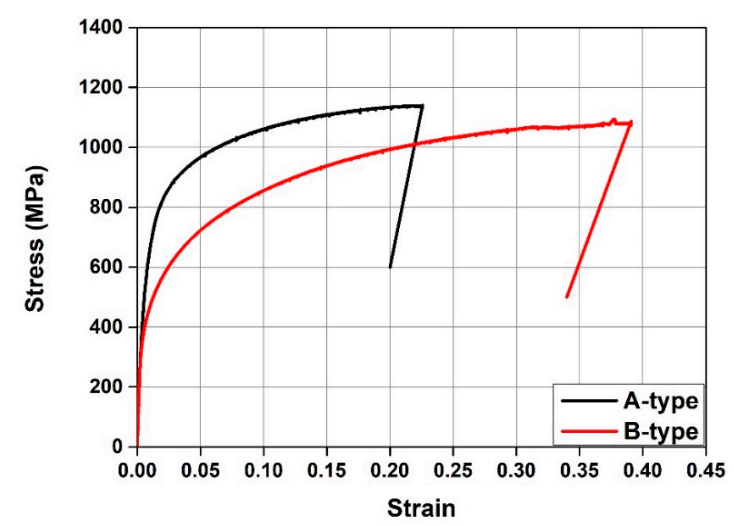

Figure 1. Stress-strain curves according to type of Fe-SMA [12].

Table 2. Mechanical properties of the Fe-SMA [12].

\begin{tabular}{lclccc}
\hline Specimen & $\begin{array}{c}\text { Elastic Modulus } \\
\text { (GPa) }\end{array}$ & $\begin{array}{l}\text { Yield } \\
\text { Strain }\end{array}$ & $\begin{array}{c}\text { Yield Stress } \\
\text { (MPa) }\end{array}$ & Ultimate Strain & $\begin{array}{c}\text { Ultimate Stress } \\
\text { (MPa) }\end{array}$ \\
\hline A-type & 124.57 & 0.00666 & 599 & 0.22556 & 1140 \\
B-type & 123.26 & 0.00530 & 410 & 0.39510 & 1080 \\
\hline
\end{tabular}

\subsection{Recovery Stress of $\mathrm{Fe}-\mathrm{SMAs}$}

An activation experiment was conducted to confirm the recovery stress of the Fe-SMAs used in this study. Park et al. [15] reported that ettringite between cement and fine aggregates collapsed at a temperature of $160^{\circ} \mathrm{C}$ or higher. Therefore, an appropriate heating temperature for using the $\mathrm{Fe}-\mathrm{SMAs}$ as a prestressing material was determined to be $160^{\circ} \mathrm{C}$. Considering this, recovery stress experiments were performed on the alloys at a heating temperature of $160^{\circ} \mathrm{C}$ and a prestrain level of $4 \%$. The detailed recovery stress test procedure is presented in Hong et al. [12]. Figure 2 shows the temperature-recovery stress relationship for each alloy derived from the recovery stress experiments. The maximum recovery stress $\left(\sigma_{\text {rec_max }}\right)$ and the final recovery stress $\left(\sigma_{\text {rec_final }}\right)$ of the A-type alloy were the same at $424 \mathrm{MPa}$, with little short-term relaxation. On the other hand, the maximum recovery stress and the final recovery stress of the B-type alloy were $377 \mathrm{MPa}$ and $362 \mathrm{MPa}$, respectively and short-term relaxation of about $15 \mathrm{MPa}$ occurred. In addition, the final stress of the B-type alloy was found to be about $17 \%$ smaller than that of the A-type alloy. On the other hand, it was reported in the study of Hong et al. [12] that the B-type alloy has about twice the recovery strain compared to the A-type alloy. Therefore, it is judged that the A-type alloy is suitable for an element requiring a large recovery stress, and the B-type alloy is an alloy suitable for an element requiring a large recovery strain.

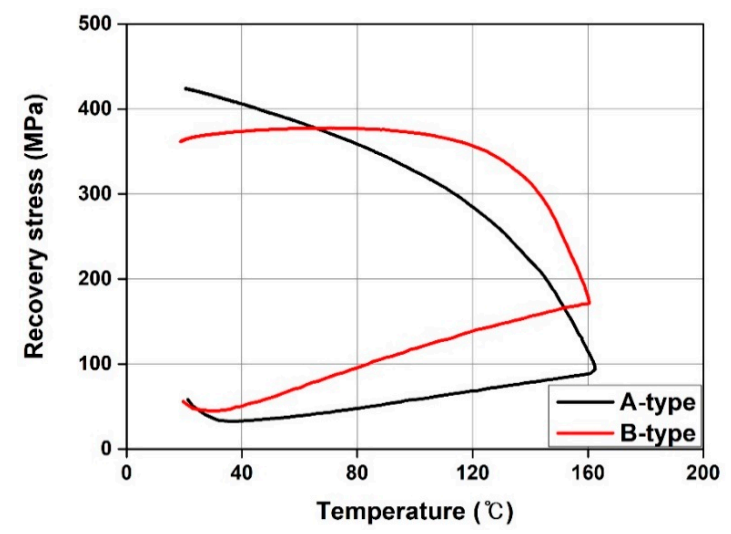

Figure 2. Recovery stress-temperature curves according to type of Fe-SMA at prestrain 0.04, heating temperature $160{ }^{\circ} \mathrm{C}[12]$. 


\section{Experimental Program}

\subsection{Test Specimen}

To confirm the fatigue characteristics of the Fe-SMAs, specimens were prepared according to ISO 12106 [16] standards. As shown in Figure 3, the width, thickness and length of the center of the specimen are $12.5 \mathrm{~mm}, 2.5 \mathrm{~mm}$ and $15 \mathrm{~mm}$, respectively, and the width and length of the jig are $17.5 \mathrm{~mm}$ and $40 \mathrm{~mm}$, respectively. In addition, a $25-\mathrm{mm}$ radius fillet was used to prevent stress concentration between the specimen and the jig connection.

\section{Unit : mm}

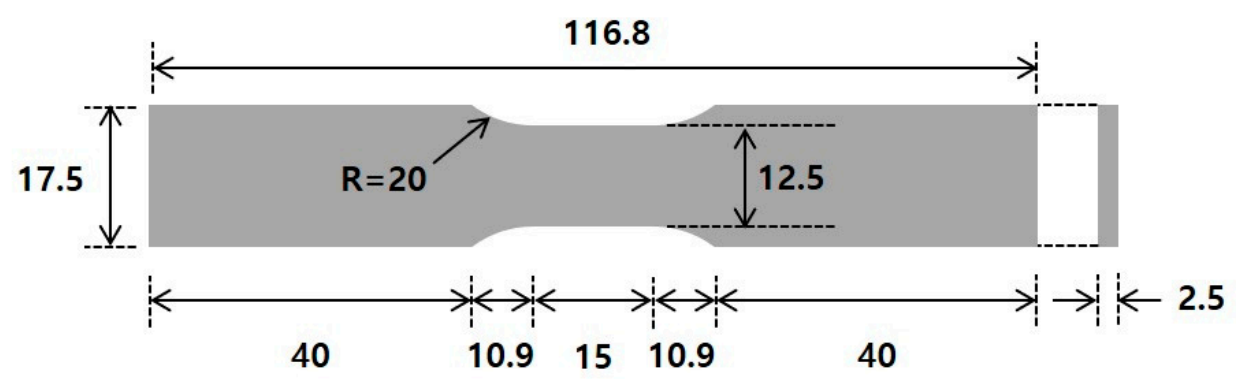

Figure 3. Shape and dimension of fatigue test specimen.

\subsection{Test Setup}

The fatigue test was conducted using a universal test machine (UTM) with a capacity of $100 \mathrm{kN}$, shown in Figure 4. The waveform of the fatigue test was sinusoidal, and all fatigue tests were conducted under a constant frequency of $5 \mathrm{~Hz}$ with a stress ratio $(\mathrm{R})$ of 0 until fracture of the specimen under the target stress range. The target stress range was reduced from $700 \mathrm{MPa}$ by $100 \mathrm{MPa}$ for each test. In addition, when the number of cycles exceeded two million times, the test was conducted by increasing the stress range by $50 \mathrm{MPa}$. After that, the stress range was increased or decreased by $25 \mathrm{MPa}$-depending on the specimen was broken or not to identify the fatigue strength. Test data were measured 100 times per second using data acquisition system (DAQ).

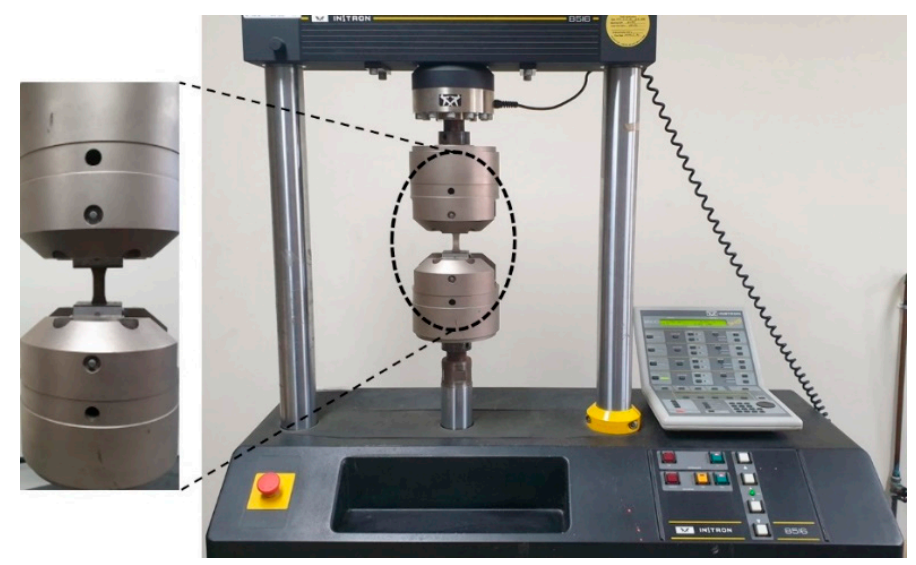

Figure 4. Test setup for fatigue tests.

\section{Result and Discussion}

\subsection{Test Result}

Table 3 summarizes the fatigue test results; Figure 5 shows the shape of the specimens after all tests were completed. Fatigue fracture occurred in eight of the 13 specimens. In particular, among the 
specimens of A-type alloy, specimens having a stress range of $500 \mathrm{MPa}$ fractured at the center of the specimen; the remaining seven specimens fractured at the beginning of the fillet. The A-type alloy specimens did not experience fatigue fracture even when the number of loading cycles exceeded two million at a stress range of $450 \mathrm{MPa}$. On the other hand, specimens of the B-type alloy did not break, even at two million cycles at a stress range of $375 \mathrm{MPa}$.

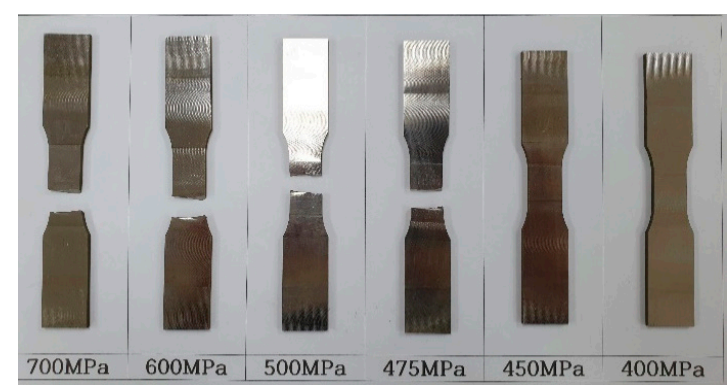

(a)

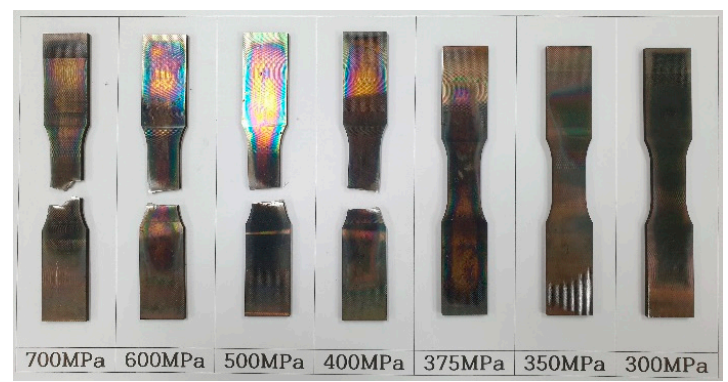

(b)

Figure 5. Test specimens after fatigue tests. (a) A-type; (b) B-type.

Table 3. Summary of fatigue test results.

\begin{tabular}{ccccc}
\hline \multirow{2}{*}{$\begin{array}{c}\text { Stress Range } \\
\text { (MPa) }\end{array}$} & \multicolumn{2}{c}{ A-Type } & \multicolumn{2}{c}{ B-Type } \\
\cline { 2 - 5 } & Number of Cycle & Log N & Number of Cycle & Log N \\
\hline 700 & 32,018 & 4.505 & 39,284 & 4.594 \\
600 & 69,580 & 4.842 & 55,769 & 4.746 \\
500 & 823,869 & 5.916 & 114,189 & 5.058 \\
475 & 677,805 & 5.831 & - & - \\
450 & $2,000,000$ & 6.301 & - & - \\
400 & $2,000,000$ & 6.301 & 418,098 & 5.621 \\
375 & - & - & $2,000,000$ & 6.301 \\
350 & - & - & $2,000,000$ & 6.301 \\
300 & - & - & $2,000,000$ & 6.301 \\
\hline
\end{tabular}

\subsection{Stress-Strain Response during Cyclic Loading}

Figure $6 \mathrm{a}, \mathrm{b}$ represents the stress-strain relationship of the A-type alloy at stress ranges of $700 \mathrm{MPa}$ and $400 \mathrm{MPa}$, respectively. As shown in Figure 6a, in a stress condition larger than the yield strength of $700 \mathrm{MPa}$, cumulative damage similar to the cyclical creep of concrete increases as the number of loading cycles increases. On the other hand, in small stress conditions below the yield strength of $400 \mathrm{MPa}$, as shown in Figure 6b, the increase in the number of cycles resulted in recovery of residual deformation resulting from the rolling process, resulting in a decrease in strain. This can be seen in the relationship between the maximum strain and the number of cycles in Figure 7. Figure 7a shows the relationship between the maximum strain $(\mathrm{M})$ and the number of cycles $(\mathrm{N})$ of the A-type alloy. At stress range of $700 \mathrm{MPa}$, the strain increases as the number of cycles increases, whereas when the stress range is $600 \mathrm{MPa}$ or less, the strain deceases gradually by fatigue strain recovery after more than 1000 cycles. Figure $7 \mathrm{~b}$ shows the relationship between the maximum strain and the number of cycles of the B-type alloy. Over 600-MPa stress range, the B-type alloy also showed a tendency of decreasing maximum strain as the number of cycles increased. On the other hand, in the stress range of $500 \mathrm{MPa}$ or less, as the number of cycles increased, the strain decreased by the recovery of residual strain. 


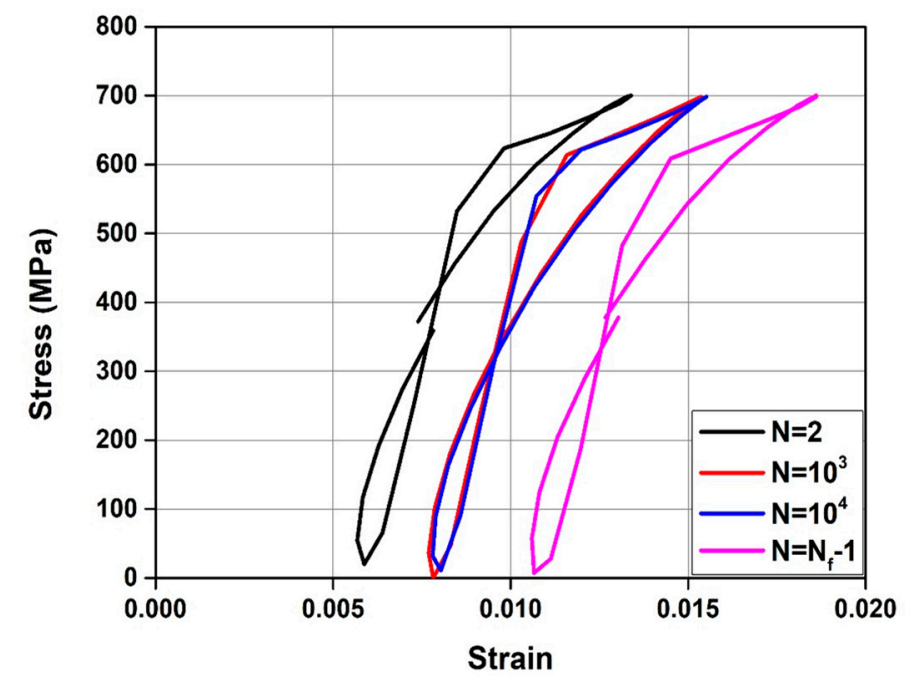

(a)

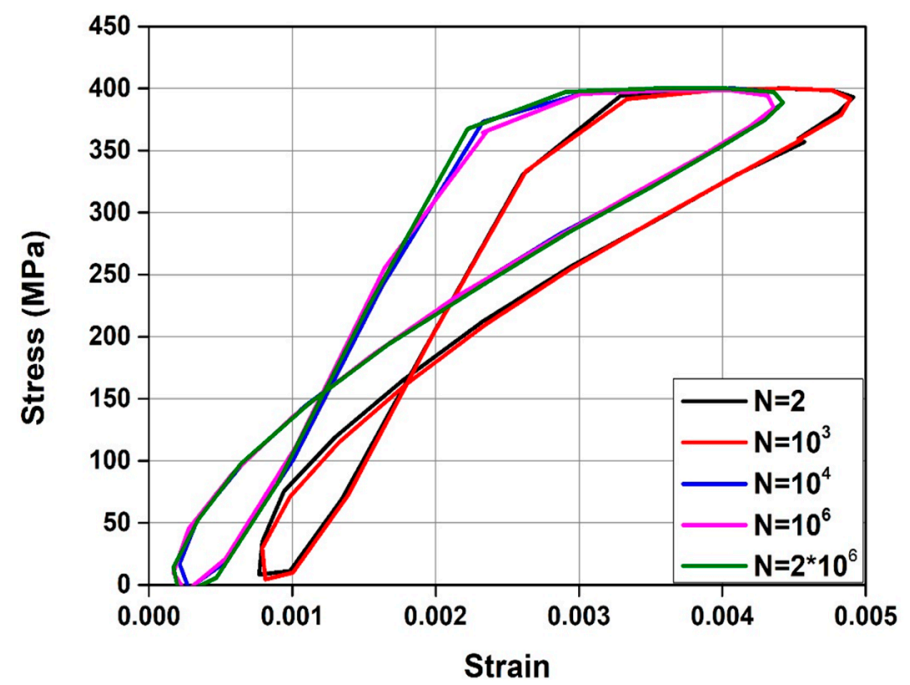

(b)

Figure 6. Stress-strain curves according to number of cycle for A-type Fe-SMA. (a) $700 \mathrm{MPa}$; (b) $400 \mathrm{MPa}$.

\subsection{Relationship between Stress Range and Number of Cycles}

As shown in Table 3, the number of cycles of the A-type and B-type alloys at stress range of $700 \mathrm{MPa}$ was 32,018 times and 39,284, respectively. On the other hand, the number of loading cycles of the A-type alloy exceeded two million under stress range of $400 \mathrm{MPa}$, whereas the number of loading cycles of the B-type alloy was 418,098. Helgason et al. [17] and Macgregor et al. [18] argued that the fatigue strength increases as the yield strength increases. As shown in Section 2.2, the A-type alloy has greater both yield and tensile strength than the B-type alloy. This difference in strength can be confirmed with the optical micrographic (OM) image in Figure 8. For OM analysis, each specimens were mechanically grinded using SiC papers. Subsequently they were polished by $3-\mu \mathrm{m}, 1-\mu \mathrm{m}$ alumina suspension and $0.04-\mu \mathrm{m}$ colloidal silica suspension. The specimens for OM were color etched by $0.5 \%$ $\mathrm{NH}_{4} \mathrm{HF}_{2}$ and $1.2 \% \mathrm{~K}_{2} \mathrm{~S}_{2} \mathrm{O}_{5}$ (mass \%) with $100 \mathrm{ml}$ of distilled water. As shown in Figure 8a,b, there is no significant difference in grain size between A-type alloy and B-type alloy, so the difference between grain size and strength according to Hall-Petch relation is considered to be irrelevant. However, as shown in Figure 8c, the strength of the B-type alloy without Ti was decreased due to the presence of many abnormal grain growth which may be formed during reheating step in hot rolling process [19]. On the other hand, abnormal grain growth could be inhibited by the formation of TiC for A-type alloy with Ti addition [14,20]. For this reason, the A-type alloy has greater strength than the B-type alloy. 
Therefore, the fatigue strength of the Fe-SMA is influenced by its strength, so that the A-type alloy with higher strength due to the formation of $\mathrm{TiC}$ has lager fatigue strength than the B-type alloy.

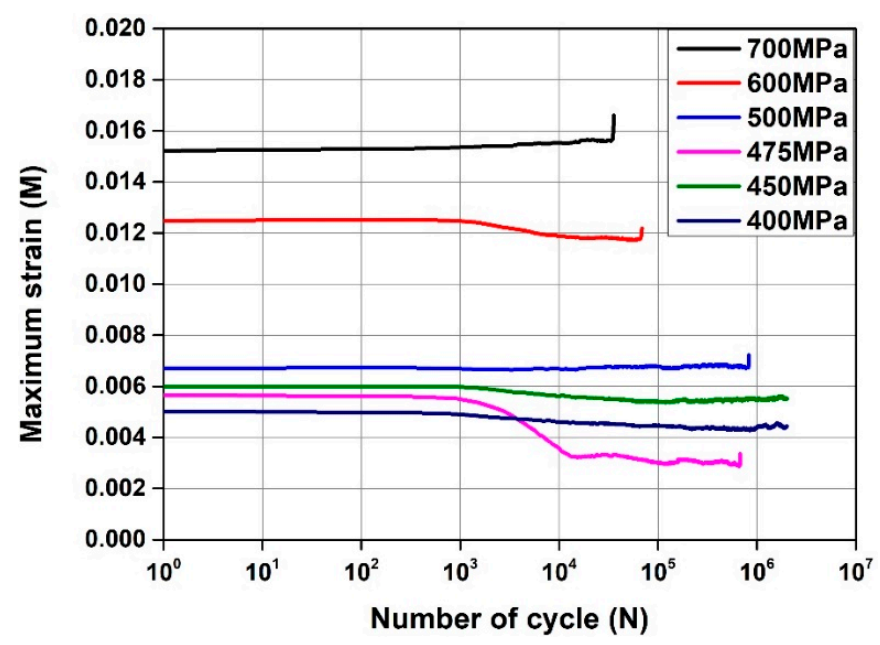

(a)

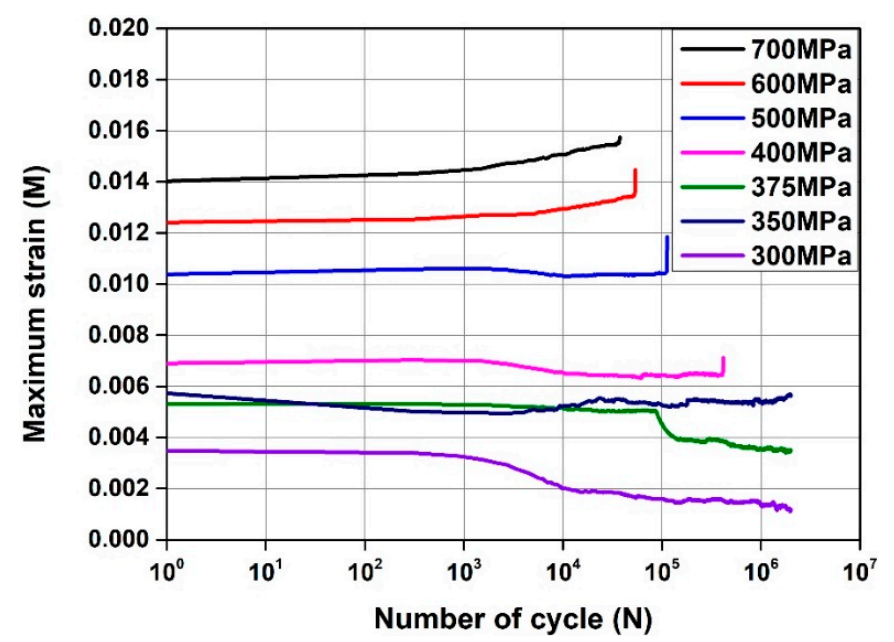

(b)

Figure 7. M-N relation according to type of alloy. (a) A-type; (b) B-type.

As shown in Figure 9a, as a result of performing a first order regression analysis using the test results, the stress range and the number of loading cycles of the A-type alloy showed the relationship delineated in Equation (1), and the coefficient of determination $\left(R^{2}\right)$ was 0.9433 . Assuming that the fatigue limit of the Fe-SMA $\left(f_{f}\right)$ is a stress range that does not break even at two million cycles, it can be obtained by substituting two million into the $\mathrm{N}$ value of Equation (1). As a result, the fatigue limit of the A-type alloy was determined to be about $473 \mathrm{MPa}$. Figure $9 \mathrm{~b}$ shows the results of the first order regression analysis using the fatigue test results of the B-type alloy. As shown in Figure 9b, the stress range and the number of cycles of the B-type alloy showed the relationship delineated in Equation (2), and the coefficient of determination $\left(R^{2}\right)$ was 0.8432 . The fatigue limit of the B-type alloy calculated in the same way as for the A-type alloy was found to be about $33 \%$ less than that of the A-type alloy. This is because the fatigue strength increases as the yield strength increases, as described above.

$$
\begin{aligned}
& S=-131.56 \log N+1265.8 \\
& S=-178.92 \log N+1456.9
\end{aligned}
$$




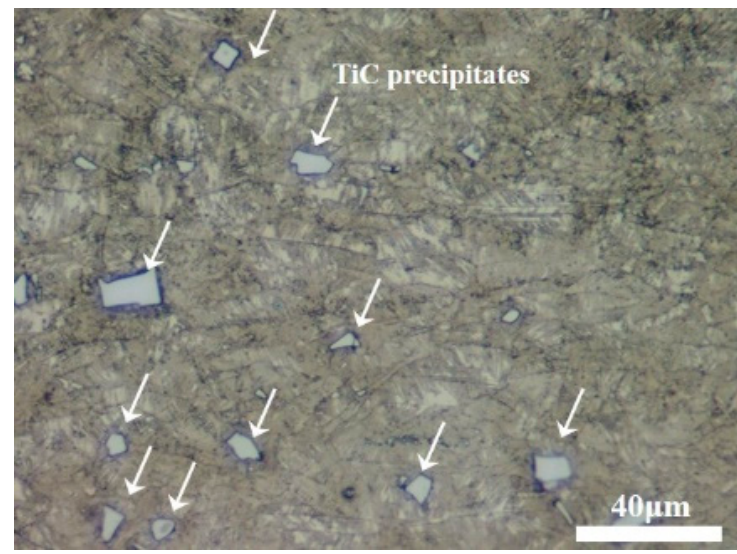

(a)

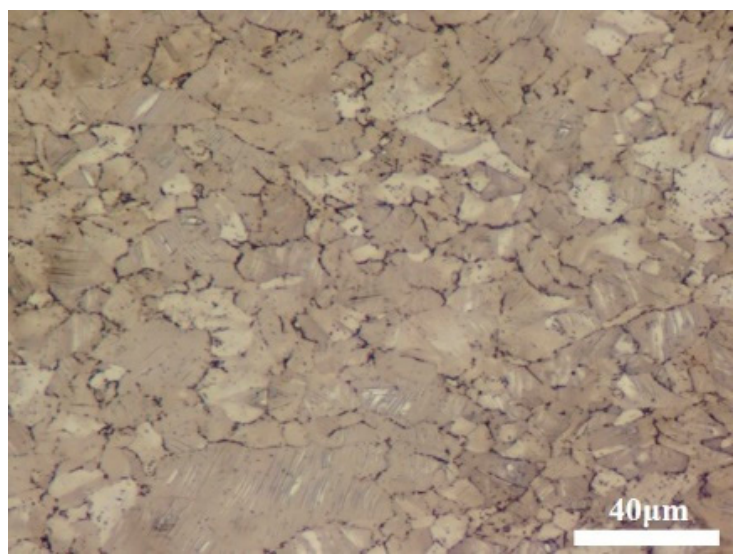

(b)

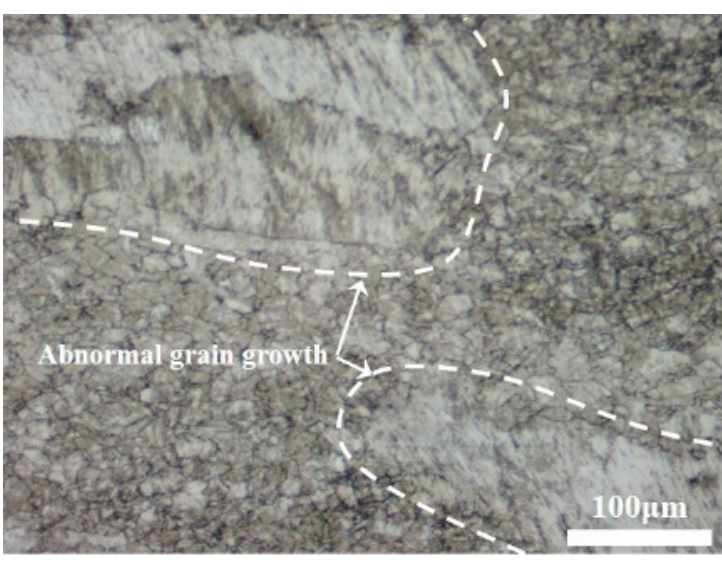

(c)

Figure 8. Optical micrographic image. (a) A-type; (b) B-type; (c) abnormal grain growth in B-type.

\section{Conclusions}

In this study, fatigue tests were conducted with aa stress ratio of zero for two types of Fe-SMAs and the following results were derived.

1. As a result of the fatigue test at a stress ratio of zero of A-type and B-type alloys, fatigue fracture occurred in a stress range between $450 \mathrm{MPa}$ and $475 \mathrm{MPa}$ for A-type alloy and between $375 \mathrm{MPa}$ and $400 \mathrm{MPa}$ for B-type alloy;

2. In a large stress range above the yield strength, the maximum strain of both the A-type and B-type alloys tends to increase as the number of loading cycles increases due to cumulative damage. In a relatively small stress range, as the residual strain of the Fe-SMA produced in the hot rolling process recovers, the maximum strain tends to decrease as the number of loading cycles increases;

3. Through a first order regression analysis of the test results, the fatigue limits of the A-type and B-type alloys were determined as $473 \mathrm{MPa}$ and $330 \mathrm{MPa}$, respectively. 


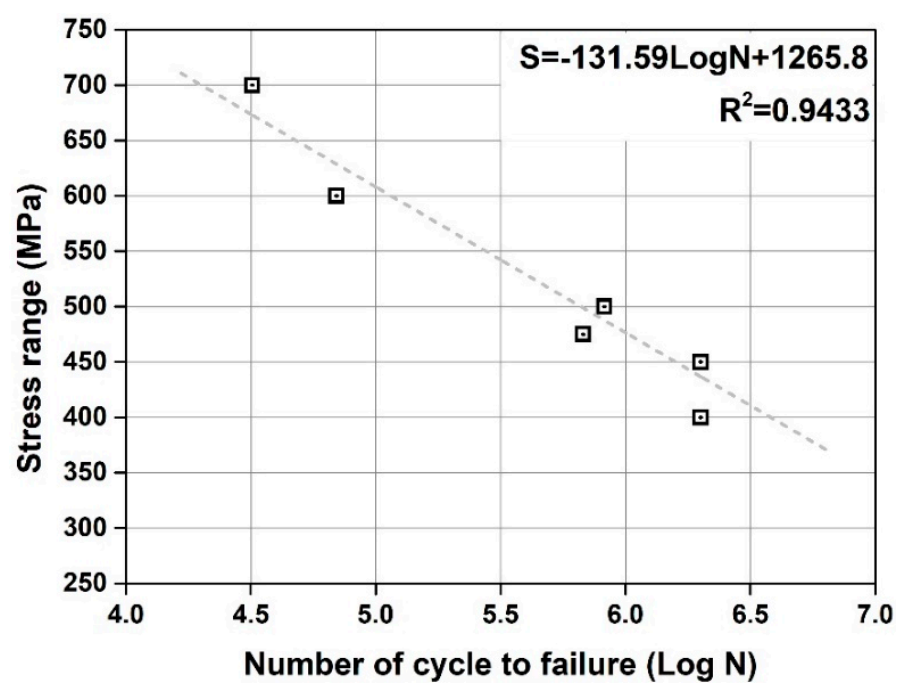

(a)

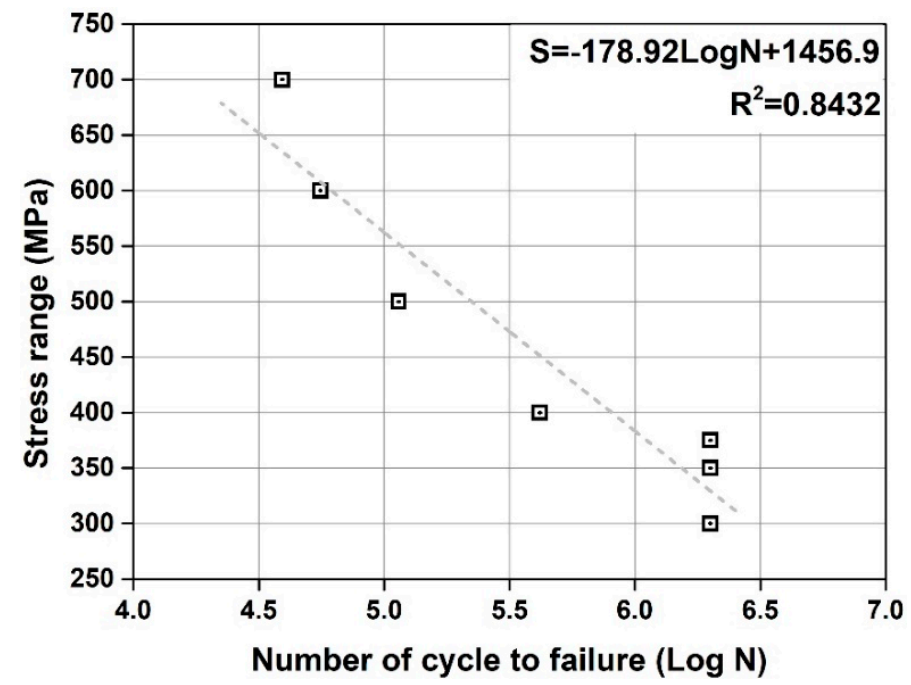

(b)

Figure 9. S-N relation according to type of alloy. (a) A-type; (b) B-type.

Author Contributions: K.-N.H. and Y.-M.Y. conceptualized the study; Y.-M.Y. obtained field data; Y.-M.Y. and W.-B.S. implemented data processing under the supervision of K.-N.H.; the original draft of the manuscript was written by K.-N.H. and Y.-M.Y. with editorial contributions from W.-B.S. and S.-W.J. All authors have read and agreed to the published version of the manuscript.

Funding: This research was funded by the Korea Agency for Infrastructure Technology Advancement (KAIA) grant funded by the Ministry of Land, Infrastructure and Transport, Republic of Korea Grant Number 20CTAP-C151899-02.

Acknowledgments: This research was supported by a grant (20CTAP-C151899-02) from Technology Advancement Research Program (TARP) funded by Ministry of Land, Infrastructure and Transport of Korean government.

Conflicts of Interest: The authors declare no conflict of interest.

\section{References}

1. Lee, W.; Weber, B.; Leinenbach, C. Recovery stress formation in a restrained Fe-Mn-Si-based shape memory alloy used for prestressing or mechanical joining. Constr. Build. Mater. 2015, 95, 600-610. [CrossRef]

2. Kim, H. Pullout Behavior of Shape Memory Alloy Fiber Embedded in Mortar Matrices. Master's Thesis, Sejong University, Seoul, Korea, 2015. 
3. Chaudhari, R.; Vora, J.J.; Patel, V.; De Lacalle, L.N.L.; Parikh, D.M. Surface Analysis of Wire-ElectricalDischarge-Machining-Processed Shape-Memory Alloys. Materials 2020, 13, 530. [CrossRef]

4. Janke, L.; Czaderski, C.; Motavalli, M.; Ruth, J. Applications of shape memory alloys in civil engineering structures-Overview, limits and new ideas. Mater. Struct. 2005, 38, 578-592. [CrossRef]

5. Czaderski, C.; Shahverdi, M.; Brönnimann, R.; Leinenbach, C.; Motavalli, M. Feasibility of iron-based shape memory alloy strips for prestressed strengthening of concrete structures. Constr. Build. Mater. 2014, 56, 94-105. [CrossRef]

6. Sato, A.; Chishima, E.; Soma, K.; Mori, T. Shape memory effect in $\gamma \rightleftarrows \epsilon$ transformation in Fe-30Mn-1Si alloy single crystals. Acta Met. 1982, 30, 1177-1183. [CrossRef]

7. Shahverdi, M.; Czaderski, C.; Motavalli, M. Iron-based shape memory alloys for prestressed near-surface mounted strengthening of reinforced concrete beams. Constr. Build. Mater. 2016, 112, 28-38. [CrossRef]

8. Rojob, H.; El-Hacha, R. Self-prestressing using iron-based shape memory alloy for flexural strengthening of reinforced concrete beams. ACI Struct. J. 2015, 114, 523-532.

9. Michels, J.; Shahverdi, M.; Czaderski, C.; El-Hacha, R. Mechanical Performance of Iron-Based Shape-Memory Alloy Ribbed Bars for Concrete Prestressing. ACI Struct. J. 2018, 115, 877-886.

10. Schranz, B.; Shahverdi, M.; Czaderski, C.; Michels, J.; Vogel, T.; Motavalli, M. Ribbed iron-based shape memory alloy bars for pre-stressed strengthening applications. In Proceedings of the International Association for Bridge and Structural Engineering Stmposium, Guimaraes, Portugal, 27-29 March 2019.

11. Byun, K.J.; Song, H.W.; Park, S.S.; Lho, B.C. A study on fatigue characteristics of domestic low-relaxtion PS strands. J. Korea Concr. Inst. 1999, 11, 113-119.

12. Hong, K.-N.; Yeon, Y.-M.; Shim, W.-B.; Kim, D.-H. Recovery Behavior of Fe-Based Shape Memory Alloys under Different Restraints. Appl. Sci. 2020, 10, 3441. [CrossRef]

13. ASTM A370-19e1. Standard Test Methods and Definitions for Mechanical Testing of Steel Products; ASTM International: West Conshohocken, PA, USA, 2019.

14. Wang, G.; Peng, H.; Sun, P.; Wang, S.; Wen, Y. Effect of titanium addition on shape memory effect and recovery stress of training-free cast Fe-Mn-Si-Cr-Ni shape memory alloys. Mater. Sci. Eng. A 2016, 657, 339-346. [CrossRef]

15. Park, S.-J.; Yim, H.J.; Kwak, H.-G. Evaluation of Microcracks in Thermal Damaged Concrete Using Nonlinear Ultrasonic Modulation Technique. J. Korea Concr. Inst. 2012, 24, 651-658. [CrossRef]

16. ISO 12106:2017(en). Metallic Materials-Fatigue Testing-Axial-Strain-Controlled Method; ISO: Geneva, Switzerland, 2017.

17. Helgason, T.; Hanson, J.M.; Somes, N.F.; Corley, W.G.; Hognestad, E. Fatigue strength of high yield reinforceing bars. In NCHRP Bulletin 164; Transportation Research Board; National Research Council: Washington, DC, USA, 1976.

18. Macgregor, J.G.; Jhamb, I.C.; Nutall, N. Fatigue strength of hot rolled deformed reinforcing bars. J. Am. Concr. Inst. 1971, 68, 169-179.

19. Asahi, H.; Yagi, A.; Ueno, M. Effect of ferrite formation on abnormal austenite grain coarsening in low-alloy steels during the hot rolling process. Met. Mater. Trans. A 1998, 29, 1375-1381. [CrossRef]

20. Han, Y.; Shi, J.; Xu, L.; Cao, W.; Dong, H. TiC precipitation induced effect on microstructure and mechanical properties in low carbon medium manganese steel. Mater. Sci. Eng. A 2011, 530, 643-651. [CrossRef]

(C) 2020 by the authors. Licensee MDPI, Basel, Switzerland. This article is an open access article distributed under the terms and conditions of the Creative Commons Attribution (CC BY) license (http://creativecommons.org/licenses/by/4.0/). 